\title{
The effect of practicing some sporting activities on the motivational traits of Top-levels Athletes
}

\section{Introduction and Research problem}

The personal characteristics have great importance in the field of sports and the motivational traits are one of the aspects that represent that importance and it is considered one of the most important topics that need to be studied due to its great role in influencing the movement behavior of Top-levels athletes in (volleyball - hockey - handball).

Osama Kamel Ratib (2007) refers to motivation as one of the most important and interesting topics of psychology for all people. It is important to the father who wants to know why his child tends to withdraw in himself and reluctance to play with his peers and it is important for a sports educator to know the motives for individuals to practice sports so that he can use these motives to develop their performance in the best way. Performance is not fruitful and good unless it satisfies the motives of the individual. (2: 71)

Mohamed Lotfy Taha (2002) affirms that motivation plays a very important role in sporting activity and that it can be emphasized that the most important conditions for enhancing the effectiveness of sports activity in competitions is to ration motivation in terms of its strength. $(12: 62,63)$

Andreas Huber (2000) believes that some traits of motivation are inherited and others are acquired from the environment surrounding the individual. (17: 1)

Through the survey of studies and research dealt with sport motivation traits, such as the study of Mohsen Ali Abu Al-Nour (1999) (8), Marwan Mustafa Rajab (2002) (13), Tariq Mohamed Badr Al-Din (2002) (4), Nabila Ahmed Mahmoud (2002) (14), Mohamed Abd Al-Hamid Bilal (2004) (11), Jean-Philippe Heuze (2006) (18), Amani Waheed Ibrahim and Sanaa Mahmoud Mamoun (2008) (3), Yasser Mohamed Hajar ( 2013) (15). By reviewing these 
studies, it becomes clear that there is no single study that examined the effect of practicing some sporting activities on the motivational traits of top-levels athletes to direct the training process and get benefit in designing training programs in (volleyball - hockey - handball).

\section{Research Objectives:}

The research aims to identify the differences between the three sports activities (volleyball - hockey - handball) in the dimensions of the motivational traits assessment scale of Top-levels athletes.

\section{Research hypotheses:}

- There are differences between the three sports activities (volleyball - hockey handball) in the dimensions of the motivational traits assessment scale of Toplevels athletes.

\section{Previous studies:}

1. Nadia Mohamed Sultan and Nabila Ahmed Mahmoud study (1999), entitled "Leadership behavior of a sports coach and its relationship to the sports motivation traits of junior handball players in Alexandria Governorate." The study aims to identify the quality of the relationship between the leadership behavior dimensions of coaches and the sports motivation traits of handball junior girls under study. The two researchers used the descriptive approach (surveys). The study sample included 90 handball players. Data collection tools are (the measure of leadership behavior of the sport coach and motivational traits assessment scale). The most important results are: the junior handball under study are distinguished by the following sports motivation traits (responsibility - conscientiousness - coaching status - trust - drive - leadership self-confidence)

2. Marwan Mustafa Rajab's study (2002) entitled "Motivational traits and their relationship to the performance of Top-levels athletes in handball". The study aims to determine the quality of the relationship between the motivational traits Top-levels athletes in handball and their level of performance during 
matches. The researcher used the descriptive approach. The study sample consisted of the first group (the international athletes in the Arab teams participating in the World Handball Championship for Men in Cairo in 1999, 80 athletes) and the second group (local athletes participating in the general league championship season 1999/2000, 70 athletes). Data collection tools are (Motivational traits assessment scale, tests to determine the performance level of Top-levels athletes in handball). The most important result is the superiority of the local level over the international level in the traits of aggression and conscientiousness).

3. Amin Mohamed Sharif study (2017) entitled "Sports motivation traits and their relationship to the characteristics of attention to playing situations among junior football players under 16 years of age." The study aims to identify the relationship between the sports motivation traits and the characteristics of attention to the playing situations of junior football players under 16 years old. The researcher used the descriptive approach. The study sample consisted of (55) junior football players under the age of 16 in Haras Al-Hodoud, Abu Qir for fertilizers, and Horses Owners clubs who are registered in the Alexandria region and participating in the Egyptian Football Federation championships. The data collection tools are (Motivational traits assessment scale and an attitude test to measure the characteristics of attention in football using a computer (designed by Amin Mohamed Sharif, 2008). The most important results are: There is a positive relationship between each of the dimensions of the Motivational traits assessment scale (drive - aggression - determination responsibility - leadership - self-confidence - emotional control - coachabilitymental toughness - conscientiousness - trust) and the total characteristics of attention to playing situations (concentration - distribution - shifting- amount stability).

\section{Research procedures:-}

Research Methodology: 
The researcher used the descriptive approach using the survey method because it is relevant to the nature of the research.

\section{Research fields: -}

\section{The human field:}

-The research sample included (199) Top-levels athletes representing three sports (volleyball - hockey - handball) from first-class clubs in the Arab Republic of Egypt. The exploratory study was conducted on (21) athletes while the basic study was conducted on (178) Athletes as shown in the following table:

\section{Table (1)}

The numerical description of the research sample according to the type of sporting activities distributed over the exploratory study and the basic study

\begin{tabular}{|l|l|l|l|l|l|l|}
\hline \multirow{2}{*}{$\begin{array}{l}\text { Sport } \\
\text { Activity }\end{array}$} & \multicolumn{2}{|l|}{ Total samples } & \multicolumn{2}{l|}{$\begin{array}{l}\text { The exploratory } \\
\text { study }\end{array}$} & \multicolumn{2}{l|}{ the basic study } \\
\cline { 2 - 8 } & Number & $\%$ & Number & $\%$ & Number & $\%$ \\
\hline volleyball & 62 & 31.16 & 6 & 9.68 & 56 & 90.32 \\
\hline hockey & 71 & 35.68 & 7 & 9.86 & 64 & 90.14 \\
\hline handball & 66 & 33.17 & 8 & 12.12 & 58 & 87.88 \\
\hline Total & 199 & 100 & 21 & 10.55 & 178 & 89.45 \\
\hline
\end{tabular}

From Table (1) of The numerical description of the research sample according to the type of sporting activities distributed over the exploratory study and the basic study, the total number of research sample was (199) Top-levels athletes, and the number of the exploratory sample was (21) athletes with a percentage $(10.55 \%)$ of the total sample size while the basic sample was (178) athletes with a percentage $(89.45 \%)$ of the total sample size.

\section{Inclusion Criteria of the sample:}

- To be a Top-levels athlete in the sports activities under study.

- To be registered in the Egyptian Federation 
- To be regular in training

Place field:

- Some clubs (Smouha - Al Ittihad Alexandria - Egypt Hockey Team, whose camp was established in Ismailia - Horse owners - Olympic - National Bank).

Time field:

- The exploratory study was conducted to calculate the scientific coefficients of the scale (truthfulness - stability) in the period from 1/12/2018 to 15/12/2018 for a period of two weeks

- The basic study was carried out on a sample of (178) Top-levels athletes from $15 / 2 / 2019$ to $22 / 4 / 2019$, where all measures were applied to them, and the data were collected in the collection form to be treated statistically.

\section{Data collection methods and tools:}

Motivational traits assessment scale: designed by "Tetco" and "Richard", quoted and modified by (Mohamed Hassan Allawi). The scale consists of (55) phrases that measure (11) traits (attachment 1) which are (drive, aggression, determination, responsibility, leadership, Self-confidence, emotional control, mental toughness, coachability, conscientiousness, trust) and the athlete answers the scale phrases on a 5-point scale (agree very much, agree, agree with medium degree, agree a little, agree very little).

\section{Scientific coefficients for the Motivational traits assessment scale:}

The exploratory study was conducted to calculate the scientific coefficients of the scale (truthfulness - stability) in the period from 1/12/2018 to 15/12/2018 for a period of two weeks.

\section{Truthfulness of the scale:}

Table (2) The coefficient of internal consistency (the coefficient of correlation of the degree of the phrase with the total sum of the dimension to which the phrase belongs) for the phrases of dimensions of the Motivational traits assessment scale for high-level athletes $(n=21)$ 


\begin{tabular}{|c|c|c|c|}
\hline Dimensions & $\begin{array}{c}\text { Phrase } \\
\text { No }\end{array}$ & Phrases & $\begin{array}{c}\text { The } \\
\text { coefficient } \\
\text { of internal } \\
\text { consistency }\end{array}$ \\
\hline \multirow{5}{*}{$\begin{array}{l}\text { The first } \\
\text { dimension } \\
\text { drive }\end{array}$} & 5 & $\begin{array}{l}\text { My performance is better in the more difficult match than in the easy } \\
\text { match. }\end{array}$ & $0.7707 * *$ \\
\hline & 16 & I want to do anything to beat the opponent. & $0.687 * *$ \\
\hline & 27 & I avoid challenging strong competitors. & $0.738 * *$ \\
\hline & 38 & $\begin{array}{l}\text { I do my best in the match to the extent that I avoid criticism from my } \\
\text { coach. }\end{array}$ & $0.731 * *$ \\
\hline & 49 & Sometimes I don't try my best to perform during a match. & $0.814 * *$ \\
\hline \multirow{5}{*}{$\begin{array}{l}\text { The second } \\
\text { dimension } \\
\text { aggression }\end{array}$} & 1 & I am an aggressive player in my playing & $0.718 * *$ \\
\hline & 12 & I fear the rival that is characterized by aggression. & $0.706 * *$ \\
\hline & 23 & I think I tend to get rough while playing. & $0.636 * *$ \\
\hline & 34 & In order to win the match, I have to play rough and tough. & $0.669 * *$ \\
\hline & 45 & I like to play rough for the opponent to be afraid of me. & $0.578 * *$ \\
\hline \multirow{5}{*}{$\begin{array}{c}\text { The third } \\
\text { dimension } \\
\text { determination }\end{array}$} & 7 & When things go wrong in the match, I give up easily. & $0.772 * *$ \\
\hline & 18 & In the match I think I put more effort than most of my team-mates. & $0.642 * *$ \\
\hline & 29 & I do training for additional periods outside of official training hours. & $0.628 * *$ \\
\hline & 40 & It seems that I am not trying my best in training or matches. & $0.588 * *$ \\
\hline & 51 & $\begin{array}{l}\text { Sometimes I apologize for not training or participating in some matches } \\
\text { for various reasons. }\end{array}$ & $0.729 * *$ \\
\hline \multirow{5}{*}{$\begin{array}{l}\text { The fourth } \\
\text { dimension } \\
\text { responsibility }\end{array}$} & 9 & $\begin{array}{l}\text { My team-mates describe me as someone who can take great } \\
\text { responsibility. }\end{array}$ & $0.705 * *$ \\
\hline & 20 & I blame others for failing to perform in the competition. & $0.644 * *$ \\
\hline & 31 & I apologize for participating in competitors with strong competitors. & $0.728 * *$ \\
\hline & 42 & I avoid blaming my colleagues for making some mistakes. & $0.665 * *$ \\
\hline & 53 & $\begin{array}{l}\text { If I was the cause of the defeat of my team, I willingly take the } \\
\text { responsibility. }\end{array}$ & $0.653 * *$ \\
\hline \multirow{5}{*}{$\begin{array}{l}\text { The fifth } \\
\text { dimension } \\
\text { leadership }\end{array}$} & 8 & I have all the specifications to lead any team. & $0.576^{* *}$ \\
\hline & 19 & I prefer that others take charge of leading the team. & $0.582 * *$ \\
\hline & 30 & I tell my colleagues when they are underperforming. & $0.742 * *$ \\
\hline & 41 & I avoid taking leadership positions in the team because it causes stress. & $0.595 * *$ \\
\hline & 52 & I make every effort to guide my team mates. & $0.572 * *$ \\
\hline \multirow{5}{*}{$\begin{array}{l}\text { The sixth } \\
\text { dimension } \\
\text { self- } \\
\text { confidence }\end{array}$} & 6 & I have great confidence in my skills and in my physical fitness. & $0.634 * *$ \\
\hline & 17 & I am disturbed by what other people think of me. & $0.664 * *$ \\
\hline & 28 & I am not sure of my self-confidence. & $0.722 * *$ \\
\hline & 39 & I have a great deal of confidence in myself. & $0.582 * *$ \\
\hline & 50 & I believe in my ability to defeat any competitor. & $0.808 * *$ \\
\hline \multirow{5}{*}{$\begin{array}{c}\text { The seventh } \\
\text { dimension } \\
\text { emotional } \\
\text { control }\end{array}$} & 3 & I feel cramped when I'm performing poorly. & $0.775^{* *}$ \\
\hline & 14 & $\begin{array}{l}\text { I get anxious and it becomes hard to return to my normal state when } \\
\text { unexpected things happen in the match. }\end{array}$ & $0.719 * *$ \\
\hline & 25 & I can stay calm even though others annoy me. & $0.667 * *$ \\
\hline & 36 & I cannot control my emotions when some people do wrong things to me. & $0.630 * *$ \\
\hline & 47 & I can control my emotions at critical times in the match. & $0.660^{* *}$ \\
\hline
\end{tabular}

** Significant at level $0.01=0.537 \quad *$ significant at level $0.05=0.423$

Table (2) (Continued) The coefficient of internal consistency (the coefficient

of correlation of the degree of the phrase with the total sum of the

dimension to which the phrase belongs) for the phrases of dimensions of the

Motivational traits assessment scale for high-level athletes $(\mathbf{n}=21)$ 
** Significant at level $0.01=0.537 *$ significant at level $0.05=0.423 * *$

From Table (2) The coefficient of internal consistency (the coefficient of correlation of the degree of the phrase with the total sum of the dimension to which the phrase belongs) for the phrases of dimensions of the motivational traits assessment scale for high-level athlete, we find high values of internal consistency coefficients which ranged between (0.578 to 0.814$)$ and these values are significant at the level of 0.01 , which indicates the Truthfulness of the phrases of the dimensions of the motivational traits assessment scale for the

\begin{tabular}{|c|c|c|c|}
\hline Dimensions & $\begin{array}{c}\text { Phrase } \\
\text { No }\end{array}$ & Phrases & $\begin{array}{c}\text { The } \\
\text { coefficient of } \\
\text { internal } \\
\text { consistency }\end{array}$ \\
\hline \multirow{5}{*}{$\begin{array}{l}\text { The eighth } \\
\text { dimension mental } \\
\text { toughness }\end{array}$} & 4 & I feel sensitive when my coach criticizes me. & $0.656 * *$ \\
\hline & 15 & I am able to do strenuous training several times a week. & $0.661 * *$ \\
\hline & 26 & It is difficult to continue vigorous training several times a week. & $0.729 * *$ \\
\hline & 37 & $\begin{array}{l}\text { I quickly recover my normal condition after the match or after } \\
\text { the coach criticized me. }\end{array}$ & $0.740 * *$ \\
\hline & 48 & $\begin{array}{l}\text { I am someone who has been known to be stubborn during the } \\
\text { match. }\end{array}$ & $0.716^{* *}$ \\
\hline \multirow{5}{*}{$\begin{array}{l}\text { The ninth } \\
\text { dimension } \\
\text { coachability }\end{array}$} & 2 & I consider training periods enjoyable and exciting. & $0.629 * *$ \\
\hline & 13 & Training is a real pleasure for me. & $0.593 * *$ \\
\hline & 24 & Repeated training sends me boredom. & $0.610 * *$ \\
\hline & 35 & I do not accept long-term training. & $0.584 * *$ \\
\hline & 46 & I consider myself an athlete who helps a coach during training. & $0.734 * *$ \\
\hline \multirow{5}{*}{$\begin{array}{l}\text { The tenth } \\
\text { dimension } \\
\text { conscientiousness }\end{array}$} & 11 & $\begin{array}{l}\text { I try to show friendliness to my coach so that he is satisfied with } \\
\text { me. }\end{array}$ & $0.608 * *$ \\
\hline & 22 & I often feel dereliction when I lose a match. & $0.652 * *$ \\
\hline & 23 & $\begin{array}{l}\text { I respect the team's rules and regulations even if it conflicts } \\
\text { with my interests. }\end{array}$ & $0.722 * *$ \\
\hline & 44 & $\begin{array}{l}\text { I ignore the team rules and regulations if they are not in my } \\
\text { favor. }\end{array}$ & $0.584 * *$ \\
\hline & 55 & I feel happy when my team-mates excel during the match. & $0.807 * *$ \\
\hline \multirow{5}{*}{$\begin{array}{l}\text { The eleventh } \\
\text { dimension trust }\end{array}$} & 10 & I trust others easily. & $0.702 * *$ \\
\hline & 21 & I doubt others easily. & $0.594 * *$ \\
\hline & 32 & It is difficult for others to trust me for a reason I don't know. & $0.716 * *$ \\
\hline & 43 & It is Easy for others to trust me. & $0.711 * *$ \\
\hline & 54 & I cannot interact with others to a great degree. & $0.632 * *$ \\
\hline
\end{tabular}


Top-levels athletes, and that the phrases are Truthful and correlated to the total sum of the dimension and therefore they all measure what the dimension measures and therefore the phrases are characterized by Truthfulness.

Stability of the scale:

Table (3)

Cronbach's coefficient alpha for the dimensions of the motivational traits assessment scale for high-level athletes $(n=21)$

\begin{tabular}{|l|c|l|}
\hline \multirow{2}{*}{ Dimensions } & \multicolumn{2}{|c|}{ Cronbach's coefficient alpha } \\
\cline { 2 - 2 } & For the dimensions & For the scale \\
\hline drive & 0.789 & \\
\hline aggression & 0.761 & \\
\hline determination & 0.776 & \multirow{2}{*}{0.886} \\
\hline responsibility & 0.758 & \\
\hline leadership & 0.766 & \\
\hline Self-confidence & 0.808 & \\
\hline emotional control & 0.789 & \\
\cline { 1 - 2 } mental toughness & 0.741 & \\
\hline coachability & 0.739 & \\
\hline conscientiousness & 0.837 & \\
\hline trust & 0.821 & \\
\hline
\end{tabular}

From Table (3) of Cronbach's coefficient alpha for the dimensions of the motivational traits assessment scale for high-level athletes, it is noticed the high values of the Cronback's coefficient alpha of the dimensions between (0.739 to 0.837$)$ and these values are greater than 0.700 , which confirms that the dimensions are stable and that they are as integrated contribute to building the axes and the value of coefficient alpha for the scale was (0.886), and this value is greater than the coefficient alpha of the dimensions, which confirms that the dimensions are homogeneous with each other and are stable and that they are as integrated contribute to building the scale and that any deletion or 
addition to any of these dimensions may negatively affect building the scale as a whole

\section{The basic study: -}

The basic study was conducted on a sample of (178) Top-levels athletes in the period between the period from $15 / 2 / 2019$ to $22 / 4 / 2019$, where all measures were applied to them, and the data were collected in the collection form prepared for this to be treated statistically.

Statistical analysis:

To achieve the aim of the research and its hypotheses, the necessary data were collected and statistical analyzed using the spss statistical program to get:

- Measures of central tendency (arithmetic mean - standard deviation median - flattening coefficient - Skewness coefficient)

- Pearson correlation coefficient.

- Cronbach's coefficient alpha

- Stepwise multiple regression coefficient.

- Prediction equations.

\section{Results and Discussion:}

Table (4)

Analysis of variance (ANOVA) between the three sports activities (volleyball - hockey - handball) in the dimensions of motivational traits assessment scale for high-level athlete

\begin{tabular}{|l|r|c|c|c|c|c|c|}
\hline Dimensions & Source of variance & $\begin{array}{c}\text { Degree } \\
\text { of } \\
\text { freedom }\end{array}$ & $\begin{array}{c}\text { Sum of } \\
\text { squares }\end{array}$ & $\begin{array}{c}\text { Mean of } \\
\text { squares }\end{array}$ & $\begin{array}{c}\text { Value } \\
\text { of T }\end{array}$ & $\begin{array}{c}\text { Significant } \\
\text { differences }\end{array}$ & $\begin{array}{c}\text { Signifi } \\
\text { cance }\end{array}$ \\
\hline drive & Between activities & 2 & 204.38 & 102.19 & $11.94^{*}$ & 0.00 & Sig. \\
\cline { 2 - 9 } & Inside activities & 175 & 1497.65 & 8.56 & & & \\
\cline { 2 - 9 } & Sum & 177 & 1702.03 & & & & \\
\hline aggression & Between activities & 2 & 200.96 & 100.48 & $5.25^{*}$ & 0.01 & Sig. \\
\cline { 2 - 8 } & Inside activities & 175 & 3351.56 & 19.15 & & & \\
\cline { 2 - 8 } & Sum & 177 & 3552.52 & & & & \\
\hline
\end{tabular}




\begin{tabular}{|c|c|c|c|c|c|c|c|}
\hline \multirow[t]{3}{*}{ determination } & Between activities & 2 & 323.99 & 161.99 & $18.06^{*}$ & 0.00 & Sig. \\
\hline & Inside activities & 175 & 1569.95 & 8.97 & & & \\
\hline & Sum & 177 & 1893.94 & & & & \\
\hline \multirow[t]{3}{*}{ responsibility } & Between activities & 2 & 204.11 & 102.06 & $14.25 *$ & 0.00 & Siq. \\
\hline & Inside activities & 175 & 1253.20 & 7.16 & & & \\
\hline & Sum & 177 & 1457.31 & & & & \\
\hline \multirow[t]{3}{*}{ leadership } & Between activities & 2 & 62.83 & 31.42 & $3.66^{*}$ & 0.03 & Sig. \\
\hline & Inside activities & 175 & 1503.89 & 8.59 & & & \\
\hline & Sum & 177 & 1566.72 & & & & \\
\hline \multirow[t]{3}{*}{ Self-confidence } & Between activities & 2 & 168.66 & 84.33 & $11.39^{*}$ & 0.00 & Sia. \\
\hline & Inside activities & 175 & 1295.95 & 7.41 & & & \\
\hline & Sum & 177 & 1464.61 & & & & \\
\hline \multirow[t]{3}{*}{ emotional control } & Between activities & 2 & 112.47 & 56.23 & $11.00^{*}$ & 0.00 & Sig. \\
\hline & Inside activities & 175 & 894.80 & 5.11 & & & \\
\hline & Sum & 177 & 1007.26 & & & & \\
\hline \multirow[t]{3}{*}{ mental toughness } & Between activities & 2 & 115.22 & 57.61 & $5.83^{*}$ & 0.00 & Sig. \\
\hline & Inside activities & 175 & 1728.81 & 9.88 & & & \\
\hline & Sum & 177 & 1844.03 & & & & \\
\hline \multirow[t]{3}{*}{ coachability } & Between activities & 2 & 12.72 & 6.36 & 0.60 & 0.55 & Non \\
\hline & Inside activities & 175 & 1854.38 & 10.60 & & & \\
\hline & Sum & 177 & 1867.10 & & & & \\
\hline \multirow[t]{3}{*}{ conscientiousness } & Between activities & 2 & 98.14 & 49.07 & $8.34 *$ & 0.00 & Sig. \\
\hline & Inside activities & 175 & 1029.65 & 5.88 & & & \\
\hline & Sum & 177 & 1127.78 & & & & \\
\hline \multirow[t]{3}{*}{ trust } & Between activities & 2 & 170.97 & 85.48 & $7.28^{*}$ & 0.00 & Sia. \\
\hline & Inside activities & 175 & 2053.58 & 11.73 & & & \\
\hline & Sum & 177 & 2224.54 & & & & \\
\hline
\end{tabular}

* Significance at $0.05=3.06$

From Table (4) Analysis of variance (ANOVA) between the three sports activities (volleyball - hockey - handball) in the dimensions of motivational traits assessment scale for high-level athlete, it noticed the presence of significant differences between the three sport activities (volleyball - hockey handball) in all dimensions except for (coachability), where the value of $\mathrm{F}$ was between (3.66 to 18.06) and this value is greater than the tabulated value of (F) at the level of 0.05 , and to determine the significant differences among the three sports activities (volleyball - hockey - handball) in the dimensions of the 
motivational traits assessment scale for the Top-levels athletes, Scheffe test was used in Table (5)

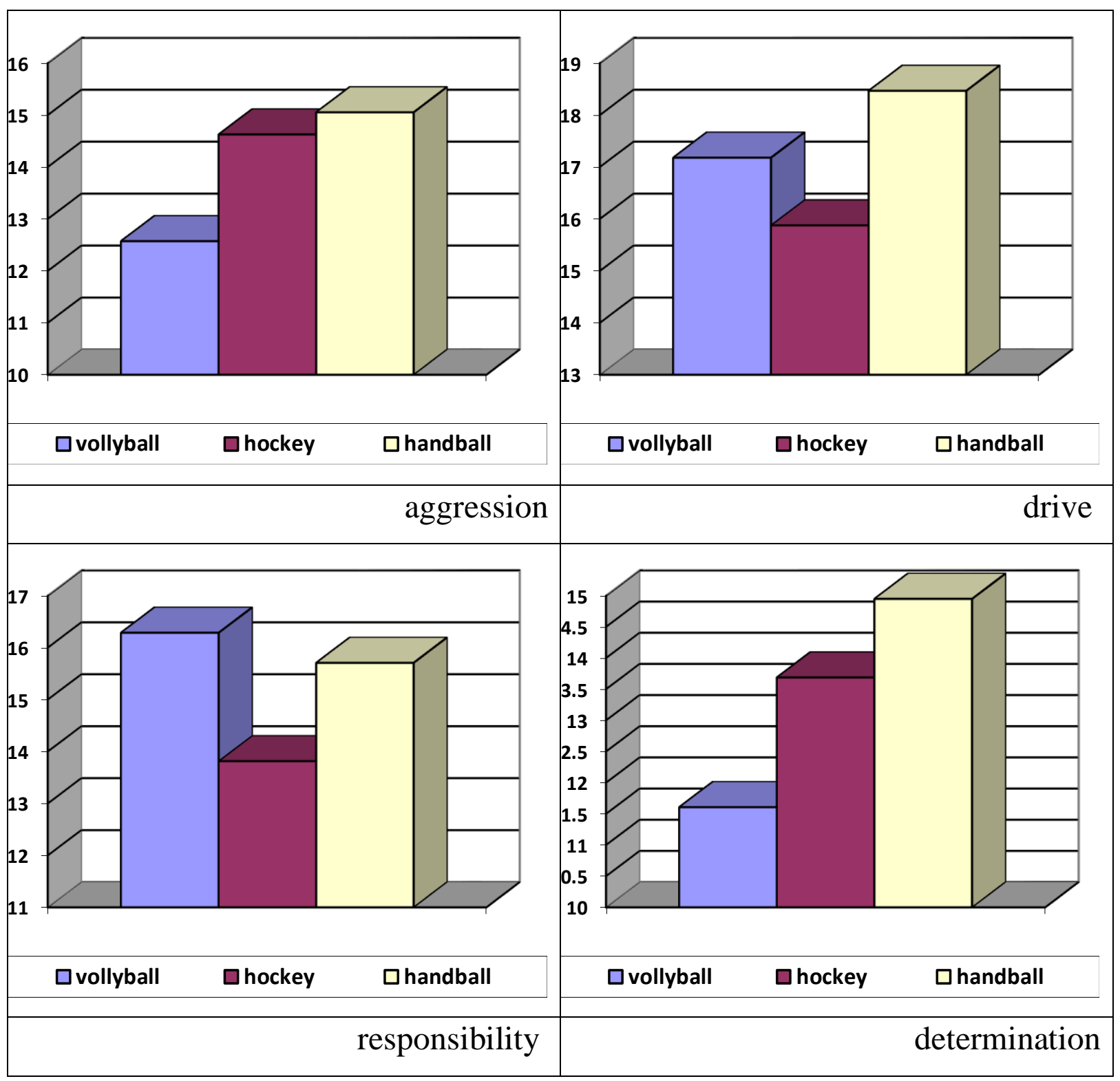




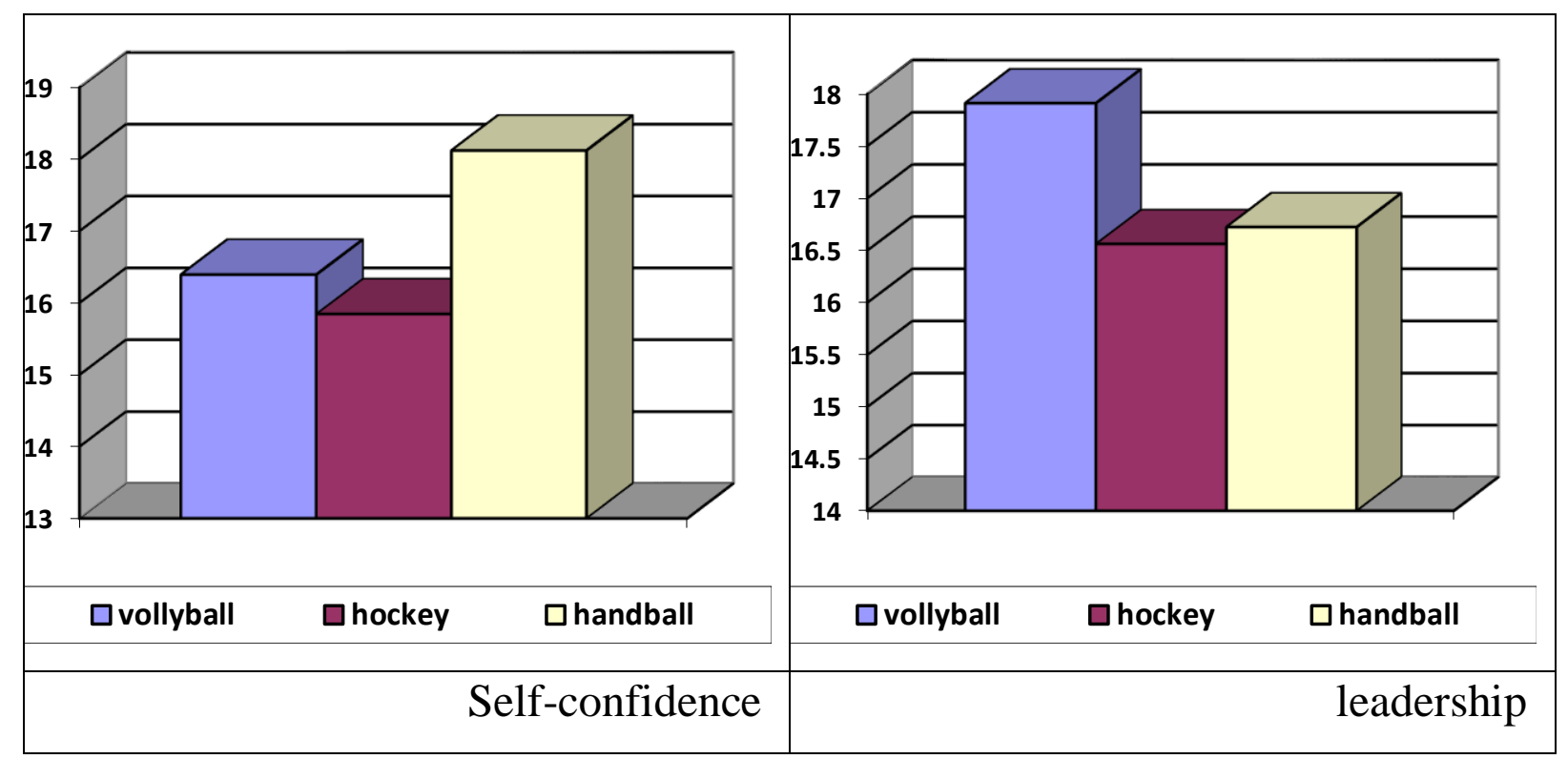

Figure (1) the arithmetic means of the three sports activities (volleyball hockey - handball) in the dimensions of Motivational traits assessment scale for Top-levels athletes

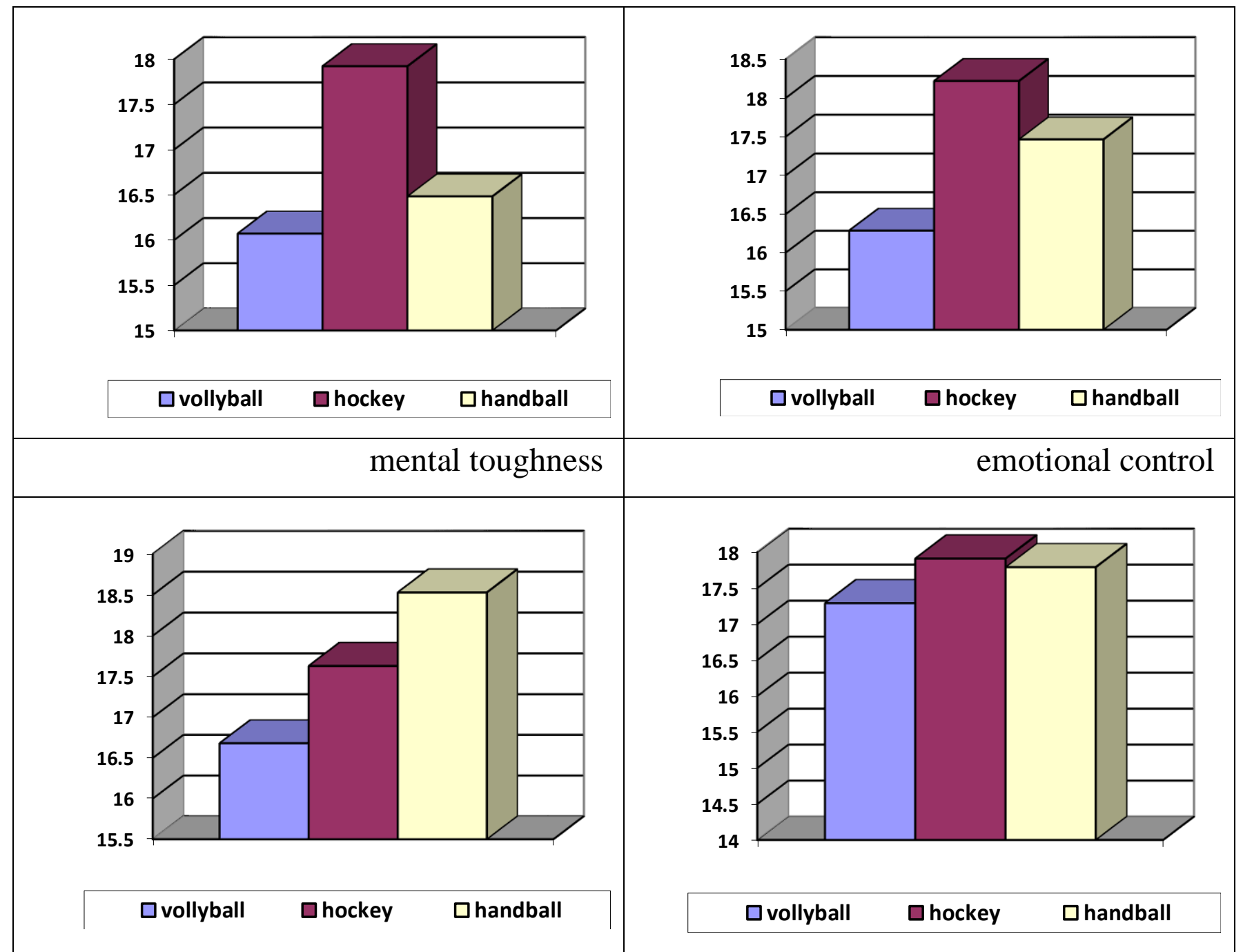




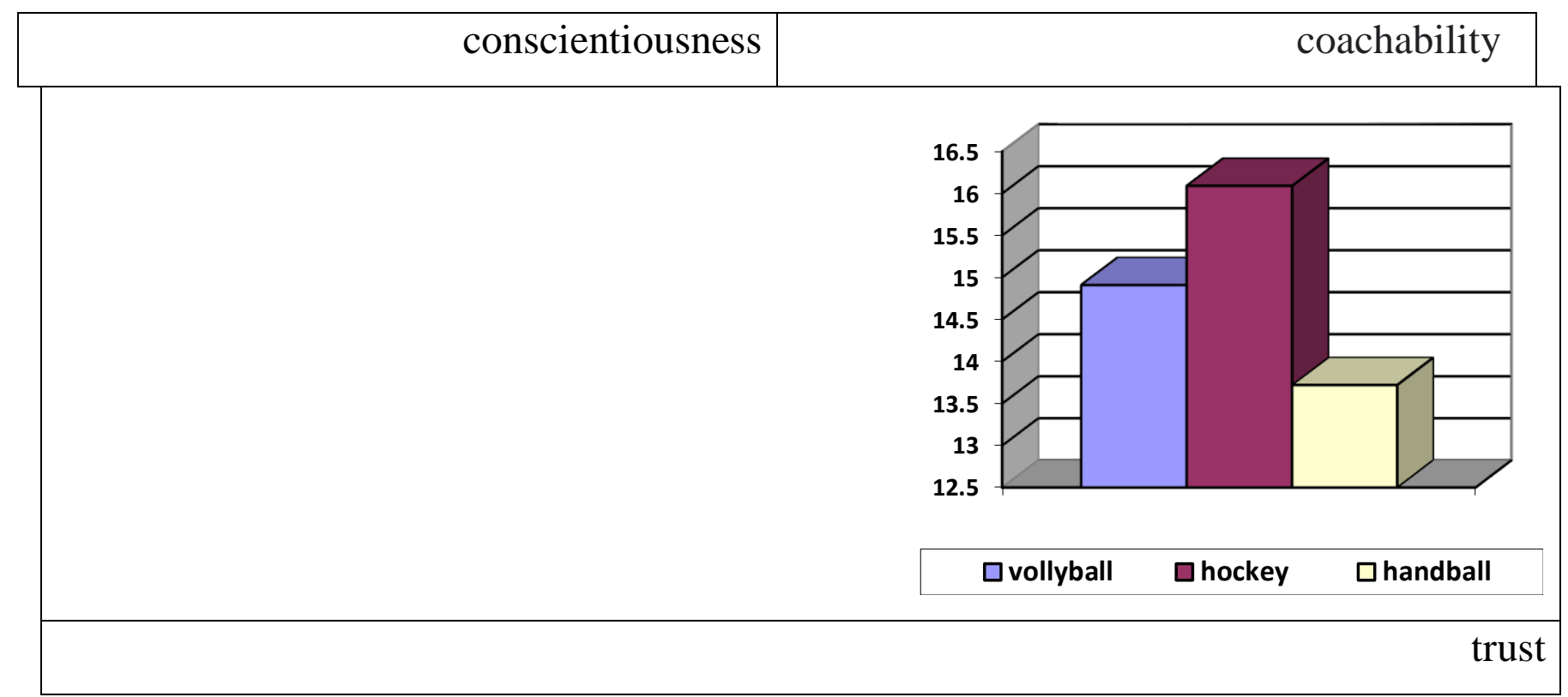

Figure (1) (continued) the arithmetic means of the three sports activities (volleyball - hockey - handball) in the dimensions of Motivational traits assessment scale for Top-levels athletes

Table (5) Significance of the differences between the means of three sport activities (volleyball hockey - handball) in the dimensions of motivational traits assessment scale for Top-levels athletes using (scheffe) test

\begin{tabular}{|c|c|c|c|c|c|c|}
\hline \multirow[t]{2}{*}{ Dimensions } & \multirow[t]{2}{*}{ groups } & \multirow{2}{*}{$\begin{array}{r}\text { Arithmetic } \\
\text { mean }\end{array}$} & \multirow{2}{*}{$\begin{array}{l}\text { Standard } \\
\text { Deviation }\end{array}$} & \multicolumn{3}{|c|}{$\begin{array}{l}\text { Significance of the differences } \\
\text { between the means (scheffe) test. }\end{array}$} \\
\hline & & & & volleyball & hockey & handball \\
\hline \multirow[t]{3}{*}{ stimulus } & volleyball & 17.18 & 2.57 & & $1.30 *$ & $1.29 *$ \\
\hline & hockey & 15.88 & 3.74 & & & $2.59 *$ \\
\hline & handball & 18.47 & 2.10 & & & \\
\hline \multirow[t]{3}{*}{ aggression } & volleyball & 12.57 & 4.86 & & $2.06 *$ & $2.48 *$ \\
\hline & hockey & 14.63 & 4.5 & & & 0.42 \\
\hline & handball & 15.05 & 3.7 & & & \\
\hline \multirow[t]{3}{*}{ determination } & volleyball & 11.61 & 2.98 & & $2.08 *$ & $3.34 *$ \\
\hline & hockey & 13.69 & 3.03 & & & $1.26 *$ \\
\hline & handball & 14.95 & 2.97 & & & \\
\hline \multirow[t]{3}{*}{ responsibility } & volleyball & 16.29 & 2.01 & & $2.48 *$ & 0.58 \\
\hline & hockey & 13.81 & 3.03 & & & $1.90 *$ \\
\hline & handball & 15.71 & 2.82 & & & \\
\hline \multirow[t]{3}{*}{ leadership } & volleyball & 17.91 & 2.5 & & $1.35 *$ & $1.19 *$ \\
\hline & hockey & 16.56 & 2.84 & & & 0.16 \\
\hline & handball & 16.72 & 3.38 & & & \\
\hline Self-confidence & volleyball & 16.39 & 2.97 & & 0.55 & $1.73 *$ \\
\hline
\end{tabular}




\begin{tabular}{|c|c|c|c|c|c|}
\hline & hockey & 15.84 & 3.28 & & $2.28 *$ \\
\hline & handball & 18.12 & 1.53 & & \\
\hline \multirow[t]{3}{*}{ emotional control } & volleyball & 16.29 & 2.3 & $1.93 *$ & $1.18 *$ \\
\hline & hockey & 18.22 & 2.03 & & 0.75 \\
\hline & handball & 17.47 & 2.46 & & \\
\hline \multirow[t]{3}{*}{ toughness } & volleyball & 16.07 & 3.69 & $1.85 *$ & 0.41 \\
\hline & hockey & 17.92 & 2.67 & & $1.44 *$ \\
\hline & handball & 16.48 & 3.05 & & \\
\hline \multirow[t]{3}{*}{ trainability } & volleyball & 17.29 & 3.32 & 0.62 & 0.5 \\
\hline & hockey & 17.91 & 3.45 & & 0.12 \\
\hline & handball & 17.79 & 2.95 & & \\
\hline \multirow[t]{3}{*}{ conscientiousness } & volleyball & 16.68 & 2.09 & $0.95 *$ & $1.85^{*}$ \\
\hline & hockey & 17.63 & 3.11 & & $0.90 *$ \\
\hline & handball & 18.53 & 1.78 & & \\
\hline \multirow[t]{3}{*}{ Trust } & volleyball & 14.91 & 3.14 & $1.18 *$ & $1.19 *$ \\
\hline & hockey & 16.09 & 3.17 & & $2.37 *$ \\
\hline & handball & 13.72 & 3.93 & & \\
\hline
\end{tabular}

From Table (5) and Figure (1) of Significance of the differences between the means of three sport activities (volleyball - hockey - handball) in the dimensions of motivational traits assessment scale for Top-levels athletes using (scheffe) test, we noted the following about the dimensions:

Drive: Handball athletes outperformed hockey and volleyball athletes significantly, and volleyball athletes outperformed hockey athletes significantly. Aggression: Handball athletes and hockey athletes outperformed volleyball athletes significantly, and we did not show significant differences between hockey athletes and handball athletes.

Determination: Handball athletes outperformed hockey and volleyball athletes significantly, and volleyball athletes outperformed hockey athletes significantly Responsibility: Handball athletes and volleyball athletes outperformed the hockey athletes significantly, and there were no significant differences between volleyball athletes and handball athletes. 
Leadership: Volleyball athletes outperformed hockey athletes and handball athletes significantly, and there were no significant differences between the hockey athletes and the handball athletes.

Self-confidence: Handball athletes outperformed hockey athletes and volleyball athletes significantly, and there were no significant differences between volleyball athletes and hockey athletes.

Emotional control: Handball athletes and hockey athletes outperformed volleyball athletes significantly and no significant differences were found between handball athletes and hockey athletes.

Mental toughness: Hockey athletes outperformed volleyball athletes and handball athletes significantly, and there were no significant differences between handball athletes and volleyball athletes.

Conscientiousness: Handball athletes outperformed hockey and volleyball athletes significantly, and hockey athletes outperformed volleyball athletes significantly.

Trust: Hockey athletes outperformed volleyball athletes and handball athletes significantly, and volleyball athletes outperformed handball athletes significantly.

The researcher believes that the sports motivational traits are important during the practice of sports activities (volleyball - hockey - handball) for Top-levels athletes, where Mohamed Hassan Allawi (2001) indicates that the mental toughness trait of the athlete appears in his ability to face difficulties and not regress in cases of defeat or unsuccessful in the match. (9: 185)

Ahmed Amin Fawzy (2006) explains that the motivation is an external issue that has a real physical or intangible existence and is in the form of a reward that is announced before the start of the sporting behavior to stimulate it. Motivation is also provided after the desired behavior is accomplished to reinforce it and increase the likelihood of it appearing in the following similar situations (1: 101) 
One of the important traits is the conscientiousness, where Mohamed Hassan Allawi (1998) pointed out that a person who attains a high degree in this trait should practice things properly whenever possible and always be dominated by a sense of duty and this type of athlete does not flatter his coach. (10:19)

Osama Kamel Ratib (2007) indicates that there are sports activities that encourage direct aggression to a limited degree. Examples of these sports activities are football, basketball, water polo, handball, where it is noticed that the player in such sports activities learns how to obstruct his opponent. Some aggressive responses are within the limits of the rules and laws of the game or sport. (2: 214)

The emotional control trait is important for Top-levels athletes under study, where Mohamed Hassan Allawi (2001) states that the self-control trait means the ability to control the individual's behavior during situations characterized by strong emotional arousal. (9: 182)

Osama Kamel Ratib (2007) noted that the leadership trait is important, as it identifies the stars who are very popular in the team, and they are considered as leaders who can influence the group, and they can take responsibilities in the team. (2: 393)

Magdy Hassan Youssef (2014) explained that self-confidence in the sports field is the confidence associated with the performance in the sports activity, and it is a degree of certainty for a player that he is able to be successful in sports competitions. (7: 141)

Singer (1984) asserted that the player's confidence in achieving of goals during his training program increases his motivation and thus his self-confidence. $(20: 16)$

Trust is important for high-level athletes. Mohamed Hassan Allawi (1998) pointed out that an athlete who has this trait is characterized by trusting what his coach and teammates say. (10:20) 
Ahmed Amin Fawzy (2006) states that a player who has the ability to emotional control will not be exposed to tension that prevents him from achieving his best possible sports performance. (1:266)

Emad Samir Mahmoud (2014) noted that the players have responsibilities and tasks for the success of the team, so the player must be familiar with the rules and laws of the game so that he can understand the reason for the referees making their decisions during the match. (6: 159)

Mohamed Hassan Allawi (1998) confirmed that coachability shows the extent of the athlete's appreciation and respect for the coach and the training process, and the extent of the athlete's compliance with the coach's advice and appreciation for training. (10:19)

Abdel Hakim Rizk Abdel Hakim and Ahmed Abdo Hassan (2015) affirm that the trait of mental toughness and determination can be developed by assigning junior athletes to perform some tasks that can only be achieved by using such traits. (5: 117)

The researcher believes that it is necessary for Top-levels athletes (volleyball hockey - handball) to have a great deal of (drive - aggression - determination responsibility - leadership - self-confidence - emotional control - mental toughness - coachability - conscientiousness - trust) according to the nature of each sport activity

\section{Conclusions- :}

1- The presence of significant differences between the three sports activities (volleyball - hockey - handball) in all dimensions except (coachability)

2- In Drive dimension: Handball athletes outperformed hockey and volleyball athletes significantly, and volleyball athletes outperformed hockey athletes in a significant way.

3- In Determination dimension: Handball athletes outperformed hockey and volleyball athletes significantly, and volleyball athletes outperformed hockey athletes significantly 
4- In Responsibility dimension: Handball athletes and volleyball athletes outperformed the hockey athletes significantly, and there were no significant differences between volleyball athletes and handball athletes.

5- In Self-confidence dimension: Handball athletes outperformed hockey athletes and volleyball athletes significantly, and there were no significant differences between volleyball athletes and hockey athletes

6- In Trust dimension: Hockey athletes outperformed volleyball athletes and handball athletes significantly, and volleyball athletes outperformed handball athletes significantly.

7- In Mental toughness: Hockey athletes outperformed volleyball athletes and handball athletes significantly, and there were no significant differences between handball athletes and volleyball athletes.

\section{Recommendations:}

In light of the conclusions reached in this research, the researcher recommends the following:

\section{The Egyptian Federations for Sports Activities under study:}

The necessity of the presence of a sports psychologist to develop the sports motivation traits within each team (volleyball - hockey - handball).

\section{2. coaches of high-level athletes (under study):}

It is necessary for the coach to apply the dimensions of the motivational traits assessment scale in sports (drive - aggression - determination - responsibility leadership - self-confidence - emotional control - mental toughness coachability - conscientiousness - trust) for Top-levels athletes.

\section{Researchers:}


Conducting more studies on sports motivational traits and their relationship to the rest of the mental processes or psychological skills that have not been studied in all sports activities.

\section{Top-levels athletes (under study):}

It is necessary Top-levels athletes to pay attention to coaches' instructions, which helps to improve sports motivational traits in the sports activities under study (volleyball - hockey - handball).

\section{First: Arabic references}

1. Ahmed Amin Fawzy: Principles of Sports Psychology (concepts - applications), first edition, Dar El- Fekr Al-Araby, Cairo, 2006.

2. Osama Kamel Ratib: Sports Psychology, "Concepts - Applications", Dar El- Fekr AlAraby, Cairo, 2007.

3. Amani Waheed Ibrahim, Sanaa Mahmoud Mamoun: Movement Innovation in Rhythmic Exercises and Its Relation to Some Sports Motivation traits, Fourth Regional Conference of the International Council for Health, Physical Education, Recreation, Sports and Movement Expression for the Middle East Region, Part IV, Faculty of Physical Education for Boys, Alexandria University, 2008.

4. Amin Mohamed Sharif: Sports motivation traits and their relationship to the characteristics of attention to playing situations among junior football players under 16 years, published research, The Scientific Journal of Sports Science and Sports Arts, Faculty of Physical Education for Girls, Helwan University, 2017, October issue No. (107) for the year 2025 (Under publication)

5. Tariq Mohamed Badr El-Din: Mental Skills and Sports motivation traits for Field and Track Competitors, The International Scientific Conference "Strategies for Selecting and Preparing Sports Talents in Light of Technological Development and the Information Revolution, Faculty of Physical Education for Boys, Alexandria University, 2002. 
6. Abdel Hakim Rizk Abdel Hakim, Ahmed Abdo Hassan: Psychological Determinants and Mental Aspects of Selecting juniors in the Sports Field, First Edition, Sports World Foundation and Publishing and Dar Al-Wafaa for the Printing World, Alexandria, 2015.

7. Emad Samir Mahmoud: Psychological preparation in the sports field (player - coach referee), first edition, Dar Al-Fekr Al-Araby., Cairo, 2014

8. Magdy Hassan Youssef: The Phenomenology of Psychological Flow in the Sports Field, First Edition, Sports World Foundation, Dar Al-Wafaa for the Printing World, Alexandria, 2014.

9. Mohsen Ali Abu Al-Nour: Predicting the level of performance of juniors in the sport of wrestling in light of its relation with the internal and external control center and some motivational traits, theories and applications, the thirty-second issue, Faculty of Physical Education for Boys, Alexandria University, 1999.

10. Mohamed Hassan Allawi: The Psychology of Training and Sports Competition, Dar AlFekr Al-Araby, Cairo, 2001.

11. : Encyclopedia of Psychological Tests for Athletes, First Edition, The Book Center for Publishing, Cairo, 1998.

12. Mohamed Abdel-Hamid Bilal: The motivational traits distinguishing athletes in various playing positions in basketball, the Eighth International Scientific Conference on Physical Education and Sports Sciences, Faculty of Physical Education for Boys, Alexandria University, 2004.

13. Mohamed Lotfy Taha: The Psychological Basis for Selecting Athletes, Cairo, 2002.

14. Marawan Mostafa Ragab: Motivational traits and their Relationship to the Performance of High-Level Handball Athletes, Master Thesis, Faculty of Physical Education for Boys, Alexandria University, 2002.

15. Nadia Mohamed Sultan, Nabila Ahmed Mahmoud: "The leadership behavior of the sports coach and its relationship to the sports motivation traits of junior handball players in Alexandria Governorate, the third international scientific conference, women's sport and future science between Impact and influence, Faculty of Physical Education for Girls, Alexandria University, 1999.

16. Nabila Ahmed Mahmoud: psychological skills Characteristic of basketball players and their relationship to sports motivation traits, Journal of the Faculty of Physical Education for Girls, issue. 22, Alexandria University, 2002.

17. Yasser Mohamed Hajar: The motivational traits and psychological skills of different swordsmen and swordswomen in the sport of fencing, Journal of the Faculty of Physical Education for Girls, Issue 47, Faculty of Physical Education for Girls, Alexandria University, 2013.

\section{Second: English References:}


18- Jean-Philippe Heuze, Philippe Sarrazin , Manuel Masiero, Nicolas Raimbault And Jean-Philippe Thomas. "The Relationships of Perceived Motivational Climate to Cohesion and Collective Efficacy in Elite Female Teams". JOURNAL OF APPLIED SPORT PSYCHOLOGY, 18: 201-218, 2006

19- Huber,A "The 16 Basic disciplines that Motivates Behavior and Define our Personality" New York, 2000.

20- Singer, R.N., Sustaining Motivation in Sport (The Youth in sport, psychological considerations series) Florida State University, 1984 